\title{
Gastric Lipoma Presenting as a Case of Gastric Outlet Obstruction and Anaemia
}

\section{Ashok C* and Pandey HI \\ Department of Surgery, Tata Main Hospital, Jamshedpur, India}

*Corresponding author: Ashok Chattoraj, Head Consultant and Unit -In- charge, Department of Surgery, Tata Main Hospital, Jamshedpur, India, Tel: +919431112883; Email: drachattoraj@tatasteel.com

\section{Case Report}

Volume 2 Issue 2

Received Date: April 30, 2018

Published Date: May 28, 2018

\section{Abstract}

Gastric lipomas are relatively rare tumours. They account for 5\% of all GIT lipomas and 3\% of all benign tumours of stomach. They are difficult to diagnose since the lipoma is located submucosally and may not be clearly seen on gastroscopy. A fullness of the gastric wall combined with clinical features of gastric outlet obstruction, anaemia due to haematemesis can lead to a suspicion of this condition. CECT scan of the abdomen and endoscopic ultrasound are good tools to diagnose this condition accurately. We encountered a case where our patient had features of both unexplained anaemia and gastric outlet obstruction and 3 endoscopies were needed to detect this condition. The patient was successfully operated upon and discharged.

Keywords: Gastric lipoma; Anaemia; Tumours of stomach; Diabetes Mellitus; Mass

\section{Introduction}

The incidence of Gastric lipomas is very rare. They account for 5\% of all GIT lipomas and 3\% of all benign tumours of stomach. A high degree of suspicion and knowledge is necessary to diagnose this curable benign condition. Recently, we had the opportunity to diagnose and treat a case of Gastric lipoma in our hospital successfully. Around 220 cases of Gastric lipoma have been described in the literature, so we felt we should share our experience.

\section{Case Description}

A 55 year old lady was admitted with complaints of black coloured stools, on and off, large volume on several occasions for 11 months, more since last 2 months. She had non bilious and projectile vomiting for 2 months and pain in abdomen, more in epigastric region for 11 months. This was associated with loss of appetite for 5 months. She had several admissions for unexplained anemia and was evaluated biochemically, endoscopically and radiologically. She underwent gastroscopy on 3 occasions for her symptoms. She is a known case of Type 2 Diabetes Mellitus and Hypertension on Tab. Glimipride- 2 mg 12 hourly, Tab. Metformin $500 \mathrm{mg} 12$ hourly, Tab. Metoprolol $25 \mathrm{mg} 12$ hourly \& Tab. Hydrochlorothiazide$25 \mathrm{mg}$ once daily. No history of any other surgery. No known drug allergy, no significant family history. Her bladder habit is normal, her sleep and appetite is normal. She had mild pallor with a $\mathrm{Hb} \%$ of $8.5 \mathrm{Gm} \%$. Her blood pressure was $126 / 84 \mathrm{~mm} \mathrm{Hg}$ at the time of surgery. There 
was no palpable lump in her abdomen. Upper GI endoscopy was done. It revealed a smooth bulge in the posterior wall of the stomach. The mass was not well defined and was compromising the lumen to a moderate degree. A biopsy was taken from the mass but it showed only normal mucosal tissue. CECT was done (Figure 1). It revealed a smooth mass over the posterior wall of the stomach. There was no lymphadenopathy. A differential diagnosis of GIST and malignancy was made at that time.
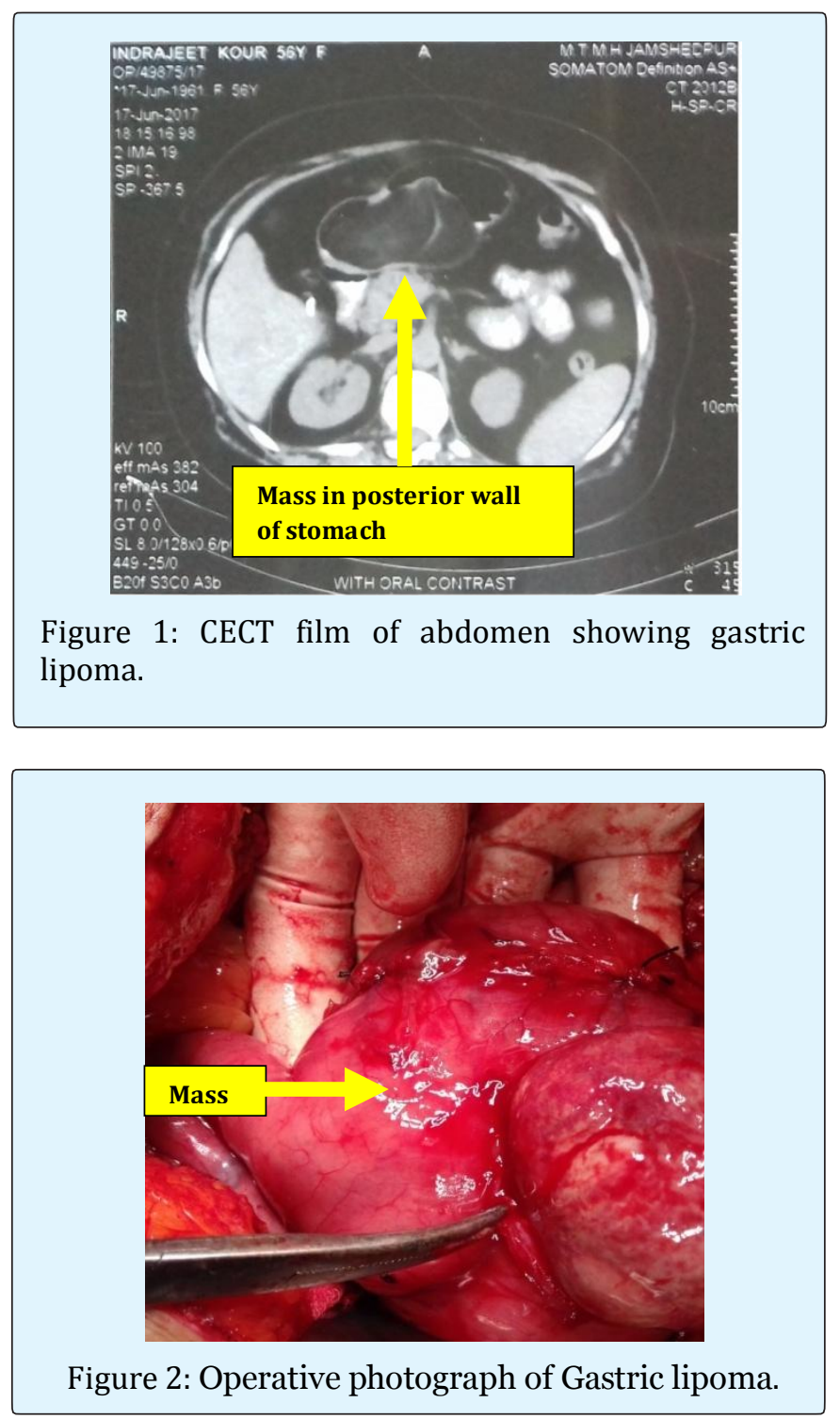

She underwent Diagnostic Laparoscopy and Exploratory Laparotomy on $2^{\text {nd }}$ February. Diagnostic laparoscopy was done to rule out peritoneal and liver metastasis. The abdomen was opened using an upper midline incision. A firm mass was felt in distal portion of the body of stomach. Gastrotomy was done. (Figures 2 \& 3) The posterior wall mucosa incised and submucosal lesion enucleated. The lesion was yellowish to white in colour, multilobulated, globular, smooth surface, firm in consistency measuring $8 \times 6 \mathrm{~cm}$. A Frozen section was sent and it was reported as LIPOMA. Closure was done.

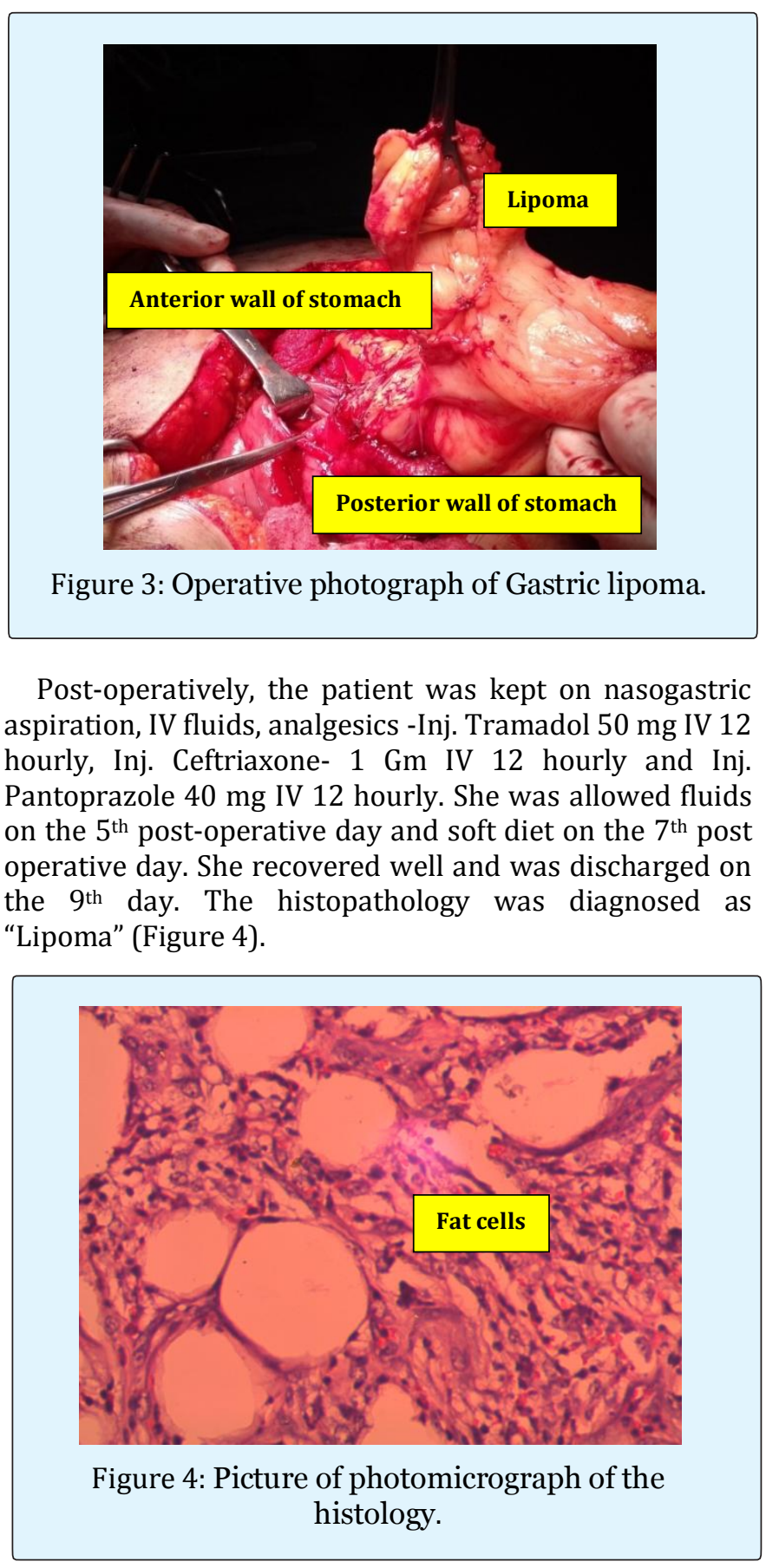




\section{International Journal of Surgery \& Surgical Techniques}

\section{Discussion}

Gastric lipoma is a rare benign gastric tumour, usually found incidentally [1,2]. Although most gastric lipomas are asymptomatic, they can cause abdominal pain, bleeding, vomiting due to pyloric obstruction, [3-8] intussusception, haematemesis and chronic anaemia $[2,3]$. Gastric lipomas are benign submucosal tumours composed of matured adipose tissue. They may occur anywhere in the gastrointestinal tract. The incidence of gastric lipoma is rare with only about 220 cases described in the literature. The first description of gastric lipoma is attributing to Cruvelhier (1842) [3]. These tumours may be found in any site of the stomach, are more commonly located in the gastric antrum, as in our case (75\%). Almost $90 \%$ cases have origin in the submucosa and the rest are intramural or subserosal [4]. Histologically, they are composed of fibrous capsule, surrounding mature adipose tissue. They account for $5 \%$ of all GIT lipomas and $3 \%$ of all benign tumours of stomach. The etiology is unclear. It may be due to adipocytes embryologically sequestered; the natural process of aging or an acquired condition $[1,5,6]$. They prevail between the $5^{\text {th }}-7^{\text {th }}$ decade with equal gender incidence $[3,4]$. In patients with larger lesion more than 3-4 cms, severe symptoms can be present.

Endoscopic findings of gastric lipoma are described as "naked fat sign" (a yellowish colour), the "tenting sign" (easy retraction of the overlying mucosa with a biopsy forceps) and the "Cushion sign" (impression after compressing the mass with biopsy forceps). Biopsy is difficult and not diagnostic, due to submucosal nature of the lesion. Generally it reveals only normal gastric mucosa $[3,6]$. Computed tomography has been shown to be valuable in the diagnostic workup. It demonstrates a well circumscribed submucosal mass with uniform fat density and attenuation ranging between -70 and $-120 \mathrm{~Hz}[2,6]$. Endoscopic ultrasound is useful for the diagnosis of gastric lipoma. It allows identification of tumours' primary layer and may reveal a possible invasion of the lymph nodes and peripheral layers. Typically lipomas are visualized as hyper echoic, homogenous lesion, that have regular margins and that arise from the $3^{\text {rd }}$ layer of the gastric wall [6].

The important differential diagnosis for gastric lipoma are 1) gastrointestinal soft tissue tumour such as GIST, leiomyoma, fibroma and their malignant variables. Gastric lipomas have no malignant potential. However synchronous gastric carcinomas have been very rarely described $[1,2,6]$. The treatment of gastric lipoma is still controversial [1]. Pedunculated lipomas which are less than $3 \mathrm{cms}$ maybe excised by upper GI endoscopy. For majority of authors, surgical resection remains the treatment of choice. For larger symptomatic gastric lipomas, laparoscopy is a minimally invasive technique used for tumours upto $6 \mathrm{~cm}$ in diameter. Laparoscopic atypical gastrectomy is the effective safe and minimally invasive technique [9-14]. Pre-operatively, endoscopically injection of China ink helps in localization of the lipoma during laparoscopic surgery due to staining of the lipoma [9-14]. Laparotomy and surgical resection is also frequently performed surgery.

\section{References}

1. Chagarlamudi K, Devita R, Barr RG (2018) Gastric Lipoma: A Review of the Literature. Ultrasound Q.

2. Ramdass MJ, Mathur S, Seetahal-Maraj P, Barrow S (2013) Gastric lipoma presenting with massive upper gastrointestinal bleeding. Case Rep Emerg Med.

3. López-Zamudio J, Leonher-Ruezga KL, RamírezGonzález LR, Razo Jiménez G, González-0jeda A, et al. (2015) Lipoma gástrico pediculado. Reporte de caso. Cir Cir 83(3):222-226.

4. Agrawal K, Soubam PS, Vaiphei K (2013) two cases of rare benign mucosal lesions of the stomach. BMJ Case Rep.

5. Oh JY, Nam KJ, Choi JC, Cho JH, Yoon SK, et al.(2008) Benign submucosal lesions of the stomach and duodenum: Imaging characteristics with endoscopic and pathologic correlation. Eur J Radiol 67(1): 112124.

6. Neto FA, Ferreira MC, Bertoncello LC, Neto AA, de Aveiro WC, et al. (2012) Gastric lipoma presenting as a giant bulging mass in an oligosymptomatic patient: a case report. J Med Case Rep 6: 317.

7. Priyadarshi RN, Anand U, Pandey MK, Chaudhary B, Kumar R (2015) Giant Gastric Lipoma Presenting as Gastric Outlet Obstruction - A Case Report. J Clin Diagn Res 9(10): 03-04.

8. Almohsin M, Meshikhes AW (2015) Gastric lipoma presenting with haematemesis. BMJ Case Rep.

9. Yamamoto T, Imakiire K, Hashiguchi S, Matsumoto J, Kadono J, et al. (2004) A rare case of gastric lipoma with early gastric canser. Intern Med 43(11): 10391041. 


\section{International Journal of Surgery \& Surgical Techniques}

10. Kim DD, Tsai AI, Otani AR, Puglia CR, Malheiros CA (2011) Gastric lipoma case report. v Bras Cir 38(3): 205-206.

11. Kang WM, Yu JC, Ma ZQ, Zhao ZR, Meng QB, et al. (2013) Laparoscopic-endoscopic cooperative surgery for gastric submucosal tumors. World J Gastroenterol 19(34): 5720-5726.

12. Olguín RR, Norero ME, Briceño E, Martínez C, Viñuela E, et al. (2013) Gastric lipoma removed by laparoscopic subtotal gastrectomy: report of one case. Rev Med Chil 141(7): 927-931.
13. Caron PH, Martins MI, Bertevello PL (2016) Preliminary analysis of hybrid laparoscopic procedure for resection of gastric submucosal tumors. Rev Col Bras Cir 43(2): 129-135.

14. Laparoscopic Atypical Gastrectomy For Symptomatic Gastric Lipoma Arnaldo Machado, André Oliva,. Manuel Carvalho, Rosa Félix, MD, Jorge Caravana, MD, General Surgery Service, Hospital does Espírito Santo E.P.E. Address: Largo Senhor da Pobreza 7000, Évora, Portugal. World Journal of Medical and Surgical Case Reports

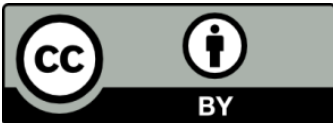

